\title{
ARR5 and ARR6 Mediate Tissue Specific Cross-talk between Auxin and Cytokinin in Arabidopsis
}

\author{
Aparna Kakani, Zhaohua Peng \\ Department of Biochemistry and Molecular Biology, Mississippi State University, Starkville, USA. \\ Email: zp7@ra.msstate.edu
}

Received July $23^{\text {rd }}, 2011$; revised September $1^{\text {st }}, 2011$; accepted September $10^{\text {th }}, 2011$.

\begin{abstract}
Auxin and cytokinin interaction plays an essential role in a wide range of plant growth and developmental processes. The interaction consequence of the two hormones is highly tissue specific. The molecular mechanisms underlying the tissue specificity are largely unknown. Here we show that the cytokinin signaling pathway key components ARR5 and ARR6 respond to auxin with a highly tissue specific and contrasted pattern in Arabidopsis seedlings and calli in the presence of cytokinin. Our results suggest that the two highly homologous but functionally distinct genes, ARR5 and ARR6, play a critical role in mediating tissue specific interaction between auxin and cytokinin.
\end{abstract}

Keywords: ARR5, ARR6, Auxin, Cytokinin, Callus, Arabidopsis, Auxin and Cytokinin Interaction

\section{Introduction}

The interplay between auxin and cytokinin is essential for plant growth and development. Their interactions includes synergistic, antagonistic and additive, depending on plant species and tissues [1-5]. Apical dominance is a classic example of auxin and cytokinin antagonistic interaction. While auxin produced at the apex represses the outgrowth of lateral buds, cytokinin applied to lateral buds promotes the release of lateral buds from apical dominance. Interestingly, auxin transported from apex promotes lateral root initiation and growth and the cytokinin produced in the root cap stimulates root apical dominance [6]. These observations suggest that interaction between auxin and cytokinin is highly tissue specific.

It has been shown that removal of the endogenous auxin source via decapitation leads to up to 40 fold increase of cytokinin in xylem exudates $[7,8]$. Studies in Arabidopsis demonstrate that auxin mediates a very rapid negative control of the cytokinin pool by mainly suppressing its biosynthesis via the isopentenyladenosine-5'mono phosphate independent pathway [9]. In addition, auxin has been found to stimulate both oxidative breakdown and glucosylation of active cytokinins in a tissuedependent manner [1]. On the other hand, an increase in free IAA (active form) has been observed both in cyto- kinin overproducing lines of Nicotiana glutinosa transformed with the bacterial cytokinin biosynthesis gene ipt (isopentenyl transferase) and in maize and pea treated with exogenously applied cytokinin [10-12], probably via cytokinin inhibition of enzymes that conjugate free IAA [13]. Meanwhile, it has also been reported that cytokinin overexpression lead to down regulation of the IAA pool in tobacco [14]. The discrepancy among different studies suggests that further investigations are required for a complete picture of the auxin-cytokinin interaction.

The auxin and cytokinin control of cell division in undifferentiated cells presents a good example of synergistic interaction of the two. Studies have shown that auxin increases the expression of a cdc2 class of cyclin-dependent kinases in tobacco pith explants. While the expression of the cdc2 like kinase is induced in response to auxin, its catalytic activity is increased only when the explants are also treated with cytokinin [15]. Cyclin $\delta 3$ is a $\mathrm{D}$ cyclin whose expression is highly dependent on cytokinin [16]. It is believed that $\delta 3$ may be the factor required to activate the cdc2 kinase. Therefore, the auxin and cytokinin synergistically control the expression and activity of the cdc2 like kinase, which renders the cell competent for cell division (review, [1]).

Kakani et al. [17] recently found that exogenous cytokinin can induce tissue specific up and down regulation 
of auxin in Arabidopsis. While auxin levels are reduced by exogenous cytokinin in cotyledons, auxin is elevated by exogenous cytokinin in roots and calli. More interestingly, they found that AUX1 plays a critical role in mediating cytokinin stimulated auxin accumulation in young roots and calli. Müller and Sheen reported that cytokinin and auxin interact antagonistically in root stem-cell specification in early embryogenesis [18]. Auxin antagonizes cytokinin signaling by directly activating the repressors of cytokinin signaling, ARR7 and ARR15. However, how cytokinin and auxin interact during shoot stem cell specification was not reported.

Both the auxin and cytokinin signaling pathways involve highly complicated networks that contain a large number of genes. The cytokinin signaling is perceived via a phosphorelay that is similar to the two-component systems used by bacteria for sensing and responding to environmental stimuli (recent review $[18,19]$ ). The pathway involves hybrid histidine protein kinases (AHK2, AHK3 and CRE1/WOL/AHK4) as receptors, histine phophotransfer proteins (AHPs), and nuclear response regulators (type A-ARRs and type B-ARRs). There are ten type-A ARR proteins (ARR3-ARR9 and ARR15ARR17) and 11 type-B ARR proteins (ARR1, ARR2, ARR10-ARR14 and ARR18-ARR21) in Arabidopsis. The type-A ARRs were originally identified as cytokinin induced genes (review, [19]). At least eight of the ten type-A ARRs are negative regulators of cytokinin signaling with overlapping function. Both gene redundancy and tissue-specific roles have been observed among typeA ARRs in cytokinin response [20-22]. ARR5 and ARR6 share highest homology with each other compared with other members in the same gene family [21]. ARR5 expression was found in the root and shoot meristems in the absence of exogenous cytokinin [23]. In the presence of exogenous cytokinin, the ARR5:GUS expression region was enlarged to include tissues around the shoot meristematic region in the shoot and all tissues in the roots, from the hypocotyl-root junction through the root tip. ARR6:GUS expression was detected in the shoot meristematic region and cotyledon vasculature in young seedlings [21]. Cytokinin treatment resulted in overall higher level expression of ARR6:GUS, including tissues in hypocotyl and root except the root tip [21]. The arr5 knockout mutant has an altered rosette morphology, which disappeared in arr 5 arr 6 double mutant, indicating that ARR 5 and ARR6 have opposite functions [21].

Although the essential role of the interplay between auxin and cytokinin in plant growth and development has been well documented, little is known of the underlying molecular mechanisms. Most of the reported studies limited to how the auxin and cytokinin levels modulated each other and in meristem tissue development. In this study, we report that the cytokinin induction of $A R R 5$ and ARR6 expression is subjected to the regulation of auxin in a tissue and gene specific manner. The distinct auxin regulatory patterns of these two highly homologous genes provide novel insights into the mechanisms underlying auxin and cytokinin interactions, especially the tissue specific interactions of these two hormones.

\section{Materials and Methods}

\subsection{Arabidopsis Growth and Callus Induction}

Arabidopsis seeds were sterilized and placed on Gamborg's B5 medium (pH 5.7) supplemented with $1 \%$ sucrose, $0.9 \%$ agar, and 2,4-D (2,4-Dichlorophenoxyacetic acid) and KT (Kinetin) as indicated in the text. After 5 days of cold treatment at $4^{\circ} \mathrm{C}$, the Petri dishes were transferred to a $22^{\circ} \mathrm{C}$ growth chamber for seed germination or callus induction under $16 \mathrm{hrs}$ of light and $8 \mathrm{hrs}$ of dark. The light intensity was $150 \mathrm{~mol} \mathrm{~m}^{-2} \mathrm{sec}^{-2}$ for germination and $50 \mathrm{~mol} \mathrm{~m}^{-2} \mathrm{sec}^{-2}$ for callus induction.

\subsection{ARR5:GUS and ARR6:GUS Transgenic Lines}

The Arabidopsis (Columbia) seeds of ARR5:GUS and ARR6:GUS lines were ordered from Arabidopsis Biological Research Center (ABRC) at the Ohio State University [21].

\subsection{Histochemical Analyses of GUS Activities}

The histochemical stain of GUS was carried out as reported by Sessions et al. [24] without sectioning. Briefly, plant materials were stained in GUS staining solution (100 mM Sodium Phosphate at pH 7.0, $10 \mathrm{mM}$ EDTA, $0.1 \%$ Triton X-100, $1 \mathrm{mM}$ potassium ferricyanide, $1 \mathrm{mM}$ potassium ferrocyanide and $1 \mathrm{mg} / \mathrm{mL}$ of X-Gluc [Gold Bio Technology, Inc.]). The samples were incubated at $37^{\circ} \mathrm{C}$ overnight after being placed under a vacuum for 10 min in a desiccator. The staining solution was removed and the tissues were cleaned by incubating with several changes of $70 \%$ ethanol. The GUS images are acquired using a Zeiss Stemi SV11 (Apo) light Microscope.

\section{Results and Discussions}

\subsection{Auxin Modulates $A R R 5$ and $A R R 6$ Expression with High Tissue Specificity and a Contrast Pattern}

In our previous studies, we found that cytokinin can induce auxin redistribution in seedlings and calli and AUX1 plays an essential role in mediating cytokinin induced auxin redistribution [17]. To examine how the cytokinin signaling pathways interact with auxin, we examined the expression of cytokinin pathway genes in response to exogenously applied auxin. ARR5 and ARR6 
share highest sequence homology in the Arabidopsis genome but may have opposite functions. We found that ARR 5 expression was in the root and shoot meristems of wild-type seedlings as reported [23] (Figure 1(a)). In the presence of $0.2 \mathrm{mg} / 1 \mathrm{KT}$, the ARR5:GUS expression was highly induced in roots, from the hypocotyl-root junction through the root tip, and regions surrounding the shoot apical meristem (Figure 1(b)). When auxin (2,4-D) was also applied, the ARR5:GUS expression in roots were strongly enhanced from the hypocotyl-root junction to root tip (Figure 1(c)-(f)). In contrast, ARR5:GUS expression in cotyledons, shoot apical meristem, and hypocotyls were suppressed.

When auxin concentration increased to $2.0 \mathrm{mg} / \mathrm{l}$, the ARR5:GUS expression was completely shut off in cotyledons and shoot apical meristem regions. But the gene expression in roots was very high.

Interestingly, auxin regulation of ARR6 expression followed a contrast pattern. In wild-type seedlings, ARR6: GUS expression was detected in the shoot apical meristematic region and cotyledon vasculature (Figure 2(a)) [21]. Cytokinin treatment elevated the expression of ARR6:GUS, particularly in hypocotyls and roots as reported (Figure 2(b)). When low auxin $(0.05 \mathrm{mg} / \mathrm{l}$ and $0.25 \mathrm{mg} / \mathrm{l}$ 2,4-D) was applied, ARR6:GUS expression was strongly induced in cotyledons, shoot apical meristem region, and hypocotyls. On the other hand, its expression in roots was suppressed starting from the elongation zone. With the increase of 2,4-D, the suppressed region extended to hypocotyl region and root tip in both directions. When 2,4-D reached $2.0 \mathrm{mg} / \mathrm{l}$, ARR6:GUS

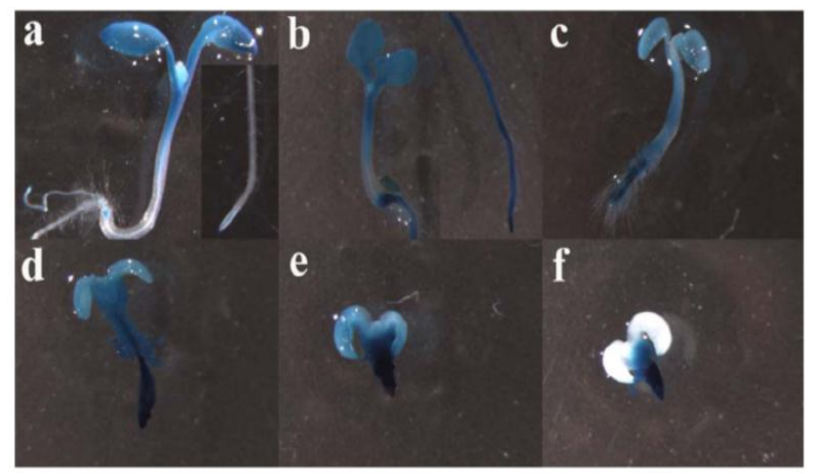

Figure 1. Histochemical assay of ARR5:GUS expression in response to cytokinin and auxin induction. The seedlings were germinated in B5 media supplemented with KT and 2, 4-D in concentrations as indicated below. The seedlings were five days old. (a) Wild-type seedling; (b) Seedling grown in medium with $0.2 \mathrm{mg} / \mathrm{l} \mathrm{KT}$; (c) Seedling grown in medium with $0.2 \mathrm{mg} / \mathrm{l} \mathrm{KT}$ and $0.05 \mathrm{mg} / \mathrm{l}$ 2,4-D. (d) Seedling grown in medium with $0.2 \mathrm{mg} / \mathrm{l} \mathrm{KT}$ and $0.25 \mathrm{mg} / \mathrm{l} \mathrm{2,4-D;} \mathrm{(e)}$ Seedling grown in medium with $0.2 \mathrm{mg} / \mathrm{l} \mathrm{KT}$ and $1.0 \mathrm{mg} / \mathrm{l} 2$, 4-D; (f) Seedling grown in medium with $0.2 \mathrm{mg} / \mathrm{l} \mathrm{KT}$ and 2.0 mg/l 2,4-D.

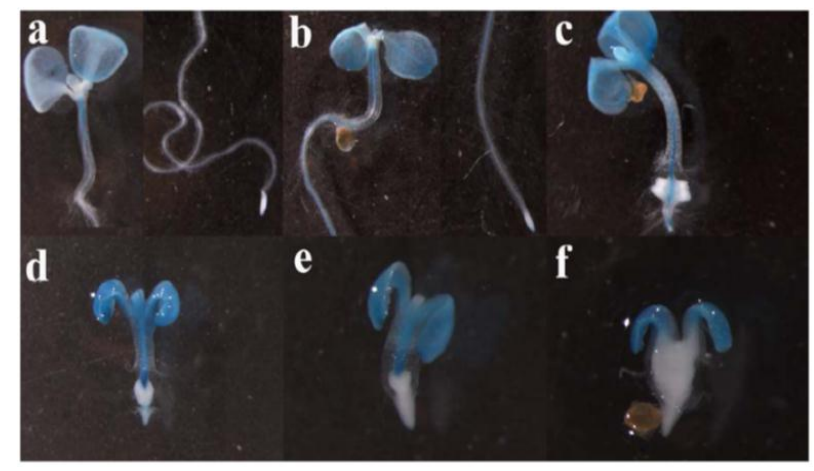

Figure 2. Histochemical assay of ARR6:GUS expression in response to cytokinin and auxin induction. The seedlings were germinated in B5 media supplemented with KT and 2, 4-D in concentrations as indicated below. The seedlings were five days old. (a) Wild-type seedling; (b) Seedling grown in medium with $0.2 \mathrm{mg} / \mathrm{l} \mathrm{KT}$; (c) Seedling grown in medium with $0.2 \mathrm{mg} / \mathrm{l} \mathrm{KT}$ and $0.05 \mathrm{mg} / \mathrm{l}$ 2,4-D. (d) Seedling grown in medium with $0.2 \mathrm{mg} / \mathrm{l} \mathrm{KT}$ and $0.25 \mathrm{mg} / \mathrm{l}$ 2,4-D; (e) Seedling grown in medium with $0.2 \mathrm{mg} / \mathrm{l} \mathrm{KT}$ and $1.0 \mathrm{mg} / \mathrm{l}$ 2, 4-D; (f) Seedling grown in medium with $0.2 \mathrm{mg} / \mathrm{l} \mathrm{KT}$ and 2.0 mg/l 2,4-D.

was expressed only in cotyledons. The expression in other tissues was almost completely suppressed. When the ARR6:GUS and ARR5:GUS expression patterns were compared (compare Figure 1 with Figure 2), it was clear that the expression of ARR5:GUS and ARR6:GUS followed a reversed pattern with the increase of auxin, suggesting a tissue specific role of these two genes in the interplay between auxin and cytokinin.

While examining the mutant phenotype in Arabidopsis [21], it was observed that the reduced rosette size of ARR5 mutant was not enhanced by the mutation of ARR6. Instead, the phenotype disappeared in the double mutant, indicating a different function of these two genes although these two genes have a high level of spatial overlapping in gene expression in cotyledons and hypocotyls in wildtype seedlings. Given that ARR5 and ARR6 negatively regulate cytokinin response, our observations suggest that auxin suppress the cytokinin stimuli in plants via modulation of the negative regulators in the cytokinin pathway. The tissue specificity of auxin and cytokinin cross-talk is achieved via differential regulation of the highly homologous genes with different functions.

\subsection{Auxin Regulation of ARR5 and ARR6 Expression in Calli}

To understand auxin and cytokinin interaction in calli, we examined the expression of ARR5:GUS and ARR6: GUS in calli induced from germinating seeds with different auxin/cytokinin ratios and culturing time. ARR5: GUS was highly expressed in calli (Figure 3). Some cells, derived from cotyledons, barely expressed ARR5 


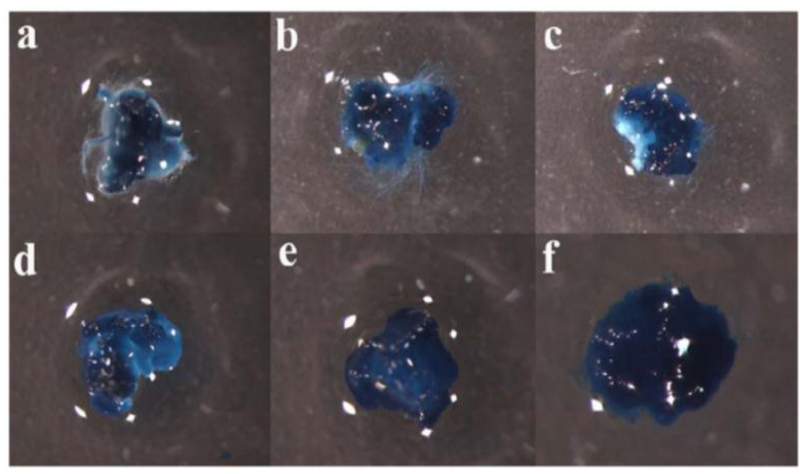

Figure 3. Histochemical assay of ARR5:GUS expression in calli. The calli were induced in B5 media supplemented with KT and 2.4-D in concentrations as indicated below. (a) Four weeks old calli induced by $0.2 \mathrm{mg} / \mathrm{l} \mathrm{KT}$ and $0.05 \mathrm{mg} / \mathrm{l} 2.4-\mathrm{D}$; (b) Four weeks old calli induced by $0.2 \mathrm{mg} / \mathrm{l} \mathrm{KT}$ and 0.25 $\mathrm{mg} / \mathrm{l} \mathrm{2.4-D;} \mathrm{(c)} \mathrm{Four} \mathrm{weeks} \mathrm{old} \mathrm{calli} \mathrm{induced} \mathrm{by} 0.2 \mathrm{mg} / \mathrm{l} \mathrm{KT}$ and $1.0 \mathrm{mg} / \mathrm{l}$ 2.4-D; (d) Four weeks old calli induced by 0.2 $\mathrm{mg} / \mathrm{l} \mathrm{KT}$ and $2.0 \mathrm{mg} / \mathrm{l}$ 2.4-D; (e) Six weeks old calli induced by $0.2 \mathrm{mg} / \mathrm{l} \mathrm{KT}$ and $2.0 \mathrm{mg} / \mathrm{l}$ 2.4-D; (f) Eight weeks old calli induced by $0.2 \mathrm{mg} / \mathrm{l} \mathrm{KT}$ and $2.0 \mathrm{mg} / \mathrm{l} 2.4-\mathrm{D}$.

initially when auxin was high. ARR5:GUS became highly expressed across the entire callus after eight weeks of culture. In contrast, the expression of ARR6: GUS in calli was low (Figure 4). Although small portion of the tissues, which derived from cotyledons, expressed ARR6:GUS initially, the GUS expression substantially decreased with time. After eight weeks, the ARR6:GUS expression was barely detected in the calli. Our results suggest that ARR5 is highly expressed in calli but ARR6 is silenced in calli.

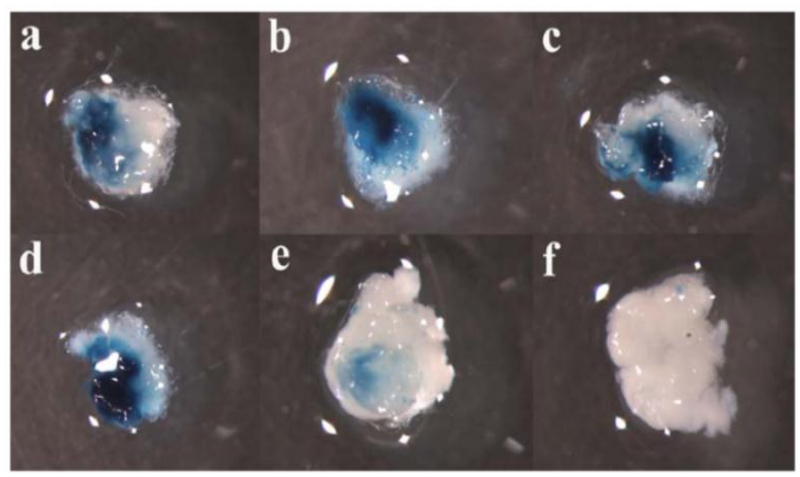

Figure 4. Histochemical assay of ARR6:GUS expression in calli. The calli were induced in B5 media supplemented with $\mathrm{KT}$ and 2.4-D in concentrations as indicated below. (a) Four weeks old calli induced by $0.2 \mathrm{mg} / \mathrm{l} \mathrm{KT}$ and $0.05 \mathrm{mg} / \mathrm{l}$ 2.4-D; (b) Four weeks old calli induced by $0.2 \mathrm{mg} / \mathrm{l} \mathrm{KT}$ and 0.25 mg/l 2.4-D; (c) Four weeks old calli induced by $0.2 \mathrm{mg} / \mathrm{l} \mathrm{KT}$ and $1.0 \mathrm{mg} / \mathrm{l}$ 2.4-D; (d) Four weeks old calli induced by 0.2 $\mathrm{mg} / \mathrm{l} \mathrm{KT}$ and $2.0 \mathrm{mg} / \mathrm{l}$ 2.4-D; (e) Six weeks old calli induced by $0.2 \mathrm{mg} / \mathrm{l} \mathrm{KT}$ and $2.0 \mathrm{mg} / \mathrm{l}$ 2.4-D; (f) Eight weeks old calli induced by $0.2 \mathrm{mg} / \mathrm{l} \mathrm{KT}$ and $2.0 \mathrm{mg} / \mathrm{l}$ 2.4-D.

\section{Conclusions}

The interaction of auxin and cytokinin is essential to plant growth and development. The molecular mechanisms underlying the interaction, particularly the tissue specific response, are still poorly understood. Our results reported here suggest that auxin interacts with the cytokinin pathway by directly regulating the expression of negative regulators ARR5 and ARR6 in the cytokinin signaling pathway. The tissue specific response is achieved by differential regulation of homologous genes with distinct functions.

\section{Acknowledgements}

We are grateful to Dr. Scott Willard, Dr. Jiaxu Li, Dr. Din-Pow Ma, and Ms Hana Mujahid for a critical reading of this manuscript. This research was approved for publication as Journal Article J-10944 of the MAFES, Mississippi State University.

\section{REFERENCES}

[1] C. Coenen and T. L. Lomax, "Auxin Cytokinin Interactions in Higher Plants: Old Problems and New Tools," Trends in Plant Science, Vol. 2, 1997, pp. 351-356. doi:10.1016/S1360-1385(97)84623-7

[2] K. Hartig and E. Beck, "Crosstalk between Auxin, Cytokinins and Sugars in the Plant Cell Cycle," Plant Biology (Stuttg), Vol. 8, No. 3, 2006, pp. 389-396. doi:10.1055/s-2006-923797

[3] R. Swarup, G. Parry, N. Graham, T. Allen and M. Bennett, "Auxin Cross-talk: Integration of Signaling Pathways to Control Plant Development," Plant Molecular Biology, Vol. 49, No. 3-4, 2002, pp. 411-426. doi:10.1023/A:1015250929138

[4] Y. -H. Su, Y. -B. Liu and X. -S. Zhang, "Auxin-Cytokinin Interaction Regulates Meristem Development," Molecular Plant, 2011.

[5] S. Perilli, L. Moubayidin and S. Sabatini, "The Molecular Basis of Cytokinin Function," Current Opinion in Plant Biology, Vol. 13, No. 1, 2010, pp. 21-26. doi:10.1016/j.pbi.2009.09.018

[6] R. Aloni, E. Aloni, M. Langhans and C. I. Ullrich, "Role of Cytokinin and Auxin in Shaping Root Architecture: Regulating Vascular Differentiation, Lateral Root Initiation," Root Apical Dominance and Root Gravitropism Annals of Botany, Vol. 97, 2006, pp. 883-893.

[7] F. Bangerth, "Response of Cytokinin Concentration in the Xylem Exudates of Bean (Phaseolus vulgaris L.) Plants to Decapitation and Auxin Treatment, and Relationship to Apical Dominance," Planta, Vol. 194, No. 4, 1994, pp. 439-442. doi:10.1007/BF00197546

[8] C. J. Li, E. Guevara, J. Herrera and F. Bangerth, "Effect of Apex Excision and Replacement by 1-Naphthy-Lacetic Acid on Cytokinin Concentration and Apical Dominance in Pea Plants," Physiologia Plantarum, Vol. 94, No. 3, 1995, pp. 465-469. 
doi:10.1111/j.1399-3054.1995.tb00955.x

[9] A. Nordstrom, P. Tarkowski, D. Tarkowska, R. Norbaek, C. Astot, K. Dolezal and G. Sandberg, "Auxin Regulation of Cytokinin Biosynthesis in Arabidopsis Thaliana: A Factor of Potential Importance for Auxin-cytokinin-Regulated Development," Proceedings of the National Academy of Sciences of the United States of America, Vol. 101, No. 21, 2004, pp. 8039-8044. doi:10.1073/pnas.0402504101

[10] G. Bertell and L. Eliasson, "Cytokinin Effects on Root-Growth and Possible Interactions with Ethylene and Indole-3-Acetic Acid," Physiologia Plantarum, Vol. 84, No. 2, 1992, pp. 255-261. doi:10.1111/j.1399-3054.1992.tb04662.x

[11] A. N. Binns, J. Labriola and R. C. Black, "Initiation of Auxin Autonomy in Nicotiana Glutinosa Cells by the Cytokinin-Biosysnthesis Gene from Agrobacterium Tumifaciens," Planta, Vol. 171, No. 4, 1987, pp. 539-548. doi:10.1007/BF00392304

[12] M. Bourquin and P. E. Pilet, "Effect of Zeatin on the Growth and Indolyl-3-Acetic Acid and Abscisic Acid Levels in Maize Roots," Physiologia Plantarum, Vol. 80, No. 3, 1990, pp. 342-349. doi:10.1111/j.1399-3054.1990.tb00051.X

[13] W. K. Yip and S. F. Yang, "Effect of Thidiazuron, a Cyto kinin-Active Urea Derivative, in Cytokinin-Dependent Ethylene Production Systems," Plant Physiology, Vol. 80, No. 2, 1986, pp. 515-519. doi:10.1104/pp.80.2.515

[14] S. Eklof, C. Astot, J. Blackwell, T. Moritz, O. Olsson and G. Sandberg, "Auxin-Cytokinin Interactions in Wildtype and Transgenic Tobacco," Plant and Cell Physiology, Vol. 38, 1997, pp. 225-235.

[15] P. C. L. John, K. Zhang, C. Dong, L. Diederich and F. Wightman, "P34 (CDC2) Related Proteins in Control of Cell Cycle Progression, the Switch between Division and Differentiation in Tissue Development and Stimulation of Division by Auxin and Cytokinin," Australian Journal of Plant Physiology, Vol. 20, No. 5, 1993, pp. 503-526. doi:10.1071/PP9930503

[16] R. Soni, J. P. Carmichael, Z. H. Shah and J. A. H. Murray, "A Family of Cyclin D-Homologs from Plants Differen- tially Controlled by Growth Regulators and Containing the Conserved Retinoblastoma Protein Interaction Motif," Plant Cell, Vol. 7, 1995, pp. 85-103.

[17] A. Kakani, G. S. Li and Z. Peng, "Role of AUX1 in the Control of Organ Identity during in vitro Organogenesis and in Mediating Tissue Specific Auxin and Cytokinin Interaction in Arabidopsis," Planta, Vol. 229, No. 3, 2009, pp. 645-657. doi:10.1007/s00425-008-0846-6

[18] B. Muller and J. Sheen, "Cytokinin and Auxin Interaction in Root Stem-Cell Specification during Early Embryogenesis," Nature, Vol. 453, 2008, pp. 1094-1097. doi:10.1038/nature06943

[19] J. P. C. To and J. J. Kieber, "Cytokinin Signaling: Two-Components and More," Trends in Plant Science, Vol. 13, 2008, pp. 85-92. doi:10.1016/j.tplants.2007.11.005

[20] P. A. Salome, J. P. C. To, J. J. Kieber and C. R. McClung, "Arabidopsis Response Regulators ARR3 and ARR4 Play Cytokinin-Independent Roles in the Control of Circadian Period," Plant Cell, Vol. 18, No. 1, 2006, pp. 55-69. doi:10.1105/tpc. 105.037994

[21] J. P. C. To, et al., "Type-A Arabidopsis Response Regulators Are Partially Redundant Negative Regulators of Cytokinin Signaling," Plant Cell, Vol. 16, No. 3, 2004, pp. 658-671. doi: $10.1105 /$ tpc.018978

[22] A. Leibfried, J. P. C. To, W. Busch, S. Stehling, A. Kehle, M. Demar, J. J. Kieber and J. U. Lohmann, "WUSCHEL" Controls Meristem Function by Direct Regulation of Cytokinin-Inducible Response Regulators," Nature, Vol. 438, 2005, pp. 1172-1175. doi:10.1038/nature04270

[23] I. B. D. Agostino, J. Deruere and J. J. Kieber, "Characterization of the Response of the Arabidopsis Response Regulator Gene Family to Cytokinin," Plant Physiology, Vol. 124, No. 4, 2000, pp. 1706-1717. doi:10.1104/pp.124.4.1706

[24] A. Sessions, D. Weigel and M. F. Yanofsky, "The Arabidopsis Thaliana Meristem Layer 1 Promoter Specifies Epidermal Expression in Meristems and Young Primordia," Plant Journal, Vol. 20, No. 2, 1999, pp. 259-263. doi:10.1046/j.1365-313x.1999.00594.x 